\title{
Aleitamento materno e prevenção de infecções
}

Maria Amélia Cunha*

\section{RESUMO}

O leite materno tem uma importância relevante na prevenção das infecções. Contém componentes imunológicos que o tornam único e inimitável.

Após o nascimento, os sistemas gastrointestinal e imunológico do recém-nascido adaptam-se à vida extra uterina mediante um processo de maturação e de desenvolvimento.

A amamentação deve ser promovida, protegida e apoiada. No entanto, há infecções maternas que a contra indicam, mas são raras e estão definidas. É o caso da infecção pelo vírus da imunodeficiência humana (VIH).

O risco do bebé contrair o VIH está a aumentar em populações de elevada prevalência e perante a falta de condições económicas, de higiene e de cuidados médicos.

Na decisão de amamentar, as mães devem considerar os benefícios da amamentação e os riscos de transmissão da doença. O profissional de saúde deve informar, orientar e apoiar as mães VIH positivas, para que façam a escolha da alimentação infantil mais segura para a sua situação. A substituição do leite materno é recomendada quando aceitável, praticável, disponível, sustentável e segura. Esta é a opção mais correcta, dada a sobrevivência do bebé ser elevada.

O citomegalovírus (CMV) pode ser encontrado no leite materno. A infecção do lactente ou do feto pode ocorrer a partir de mães com infecções primárias ou na reactivação.

A vacina do vírus da hepatite $B(V H B)$ é muito eficaz. Nas mães com antigeno de superfície da hepatite B positivo ( $\mathrm{HBs} \mathrm{Ag}$ ) não é restringida a amamentação.

Palavras-chave: Aleitamento Materno; Prevenção; Infecção; VIH; Citomegalovírus; Vírus da Hepatite B.

\section{INTRODUÇÃO}

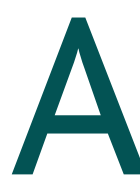
mamentar exclusivamente nos primeiros 6 meses de vida e complementar com outros alimentos até aos 2 anos de idade, ou mais, traz benefícios, não só para as crianças, como para as mães e tem um impacto significativo na saúde da família e da comunidade. ${ }^{1}$

No entanto, em determinadas condições de saúde da criança e da mãe justifica-se a recomendação que não amamente, definitiva ou temporariamente. ${ }^{1-4}$

O leite materno, cuja composição varia não só ao longo da refeição, como da hora do dia e da idade da criança, tem componentes com propriedades inimitáveis. . $, 5,6^{-10}$

Este artigo estará centrado na importância do leite materno, no seu papel na prevenção das infecções e nas recomendações sugeridas perante mães portadoras do vírus da imunodeficiência humana (VIH), do ci-

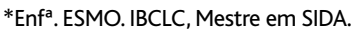

tomegalovírus (CMV) ou da hepatite B (VHB).

\section{LEITE MATERNO: UM GANHO IMUNOLÓGICO}

A glândula mamária é um órgão imunológico, que faz parte do sistema de tecidos linfóides associados a mucosas, tais como os intestinos, os pulmões, o aparelho genital, as glândulas lacrimais e as salivares. A imunização pode ser transferida de um local distante para outro através das células, especialmente pelos linfócitos. ${ }^{5}$

Ao actuar como uma extensão do tecido linfóide associado aos brônquios e aos intestinos, a glândula mamária concede ao leite materno determinados anticorpos contra microrganismos encontrados no ambiente da mãe e, posteriormente, no do recém-nascido. ${ }^{5}$

Assim, o leite materno adquire uma composição singular e específica de componentes imunológicos, ${ }^{1,7}$ que dificilmente os substitutos deste leite conseguem igua$\operatorname{lar}^{1,5}$ (Quadro I).

Estes componentes têm funções diversas e complementares entre si, sendo relevantes na prevenção das 


\section{QUADRO I. Componentes imunológicos do leite} materno (celulares e solúveis)

\begin{tabular}{|l|l} 
& Imunoglobulinas A, G, M, D e E \\
& Sistema Complemento \\
& Citocinas \\
(Interferão, Interleucinas 6, 8, 10, outras) & Factor bífido \\
Macrófago & Factor de resistência \\
Neutrófilo & Lisozima \\
Linfócito & Lactoferrina \\
Células epiteliais & Fibronectina \\
& Proteína ligadora vitamina B12 \\
& Gangliosídeos \\
& Nucleotídeos \\
& Antioxidantes \\
& Hormonas \\
\hline
\end{tabular}

Adaptado de Calvano $2005 .^{5}$

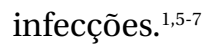

Destacam-se as propriedades anti-inflamatórias, anti-microbianas, anti-oxidantes, anti-proteases e o seu conteúdo em factores de crescimento. ${ }^{1,5,6}$

Das propriedades anti-infecciosas, salienta-se a presença dos lactobacilos e das bifidobactérias, que são bacilos gram positivos. Estes existem no leite materno; contribuem para o equilíbrio da flora intestinal (pró-bióticos) e o seu crescimento é estimulado pelo factor bífido. A multiplicação de bactérias patogénicas é inibida pela produção de ácido acético, ácido láctico, peróxido de hidrogénio e de substâncias antimicrobianas. Por outro lado, alguns lactobacilos concorrem com os microrganismos patogénicos na ligação a receptores na superfície da mucosa, contribuindo para a redução da incidência, de, por exemplo, colite e diarreia. ${ }^{1,5,6}$

Os oligossacáridos, também presentes no leite materno, são carboidratos, não digeríveis pelas enzimas intestinais e fomentam a selecção daquelas bactérias benéficas (pré-bióticos). ${ }^{1,5,6}$

Inicialmente, o intestino do recém-nascido é estéril, e irá desenvolvendo a flora intestinal saudável, gradual e lentamente ao longo do primeiro ano. Esta é fruto do desenvolvimento dos lactobacilos e das bifidobactérias e, simultaneamente, da colonização por várias estirpes

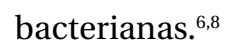

A qualidade da colonização depende da exposição às bactérias existentes no meio ambiente a que o recém-nascido fica sujeito, do tipo de parto e da alimentação. O colostro, primeiro leite materno após o parto, possui um nível elevado de anticorpos, protegendo o recém-nascido das bactérias encontradas no canal de parto. ${ }^{1,8}$

As fases críticas da colonização do intestino são os dias após o nascimento, pois a criança está mais exposta a bactérias, e os primeiros meses de vida, quando a dieta alimentar é modificada. ${ }^{8}$

A idade gestacional também é um dado importante. Assim, nos recém-nascidos grandes pré-termo ou doentes, a proliferação de bactérias patogénicas é maior, a par da imaturidade da mucosa intestinal e do retardar da constituição da flora saudável. Na maioria dos casos, estes recém-nascidos exigem a prestação de cuidados médicos e de enfermagem invasivos (cesariana, aspiração gástrica, administração de terapêutica, tipo de alimentação, outros), sendo a prevenção de infecções graves um desafio constante., ${ }^{8,9}$

O elevado grau de protecção está mais associado à amamentação exclusiva, sendo directamente proporcional ao tempo que esta dura. Os benefícios do leite materno, já demonstrados, vão desde o nascimento à idade adulta (prevenção da diabetes, da obesidade, outras). ${ }^{1}$

O contacto pele a pele mãe-bébé deve ser encorajado logo a seguir ao parto, ${ }^{1,10}$ especialmente em bebés prematuros. ${ }^{1}$ A evidência científica revela benefícios na redução de infecções mas, também, no desenvolvimento psicomotor, ganho ponderal, redução do choro e outros. ${ }^{1,11}$

Diversos estudos clínicos referem-se à colonização da flora intestinal. No entanto, não está totalmente esclarecido $^{8}$ se esta pode influenciar o sistema imune, pois além da sua complexidade, são várias as causas do risco de infecções em recém-nascidos prematuros. ${ }^{9}$

Apesar de serem necessários mais estudos, é sugerido que a terapia com os probióticos pode diminuir a incidência da enterocolite necrosante, ao optimizar a colonização intestinal. Os prematuros não ficariam tão vulneráveis às infecções. ${ }^{12}$

\section{ALEITAMENTO MATERNO E A INFECÇÃO VIH}

A nível mundial, existe uma desigualdade na promoção da saúde da criança e da família. Apesar da mortalida- 


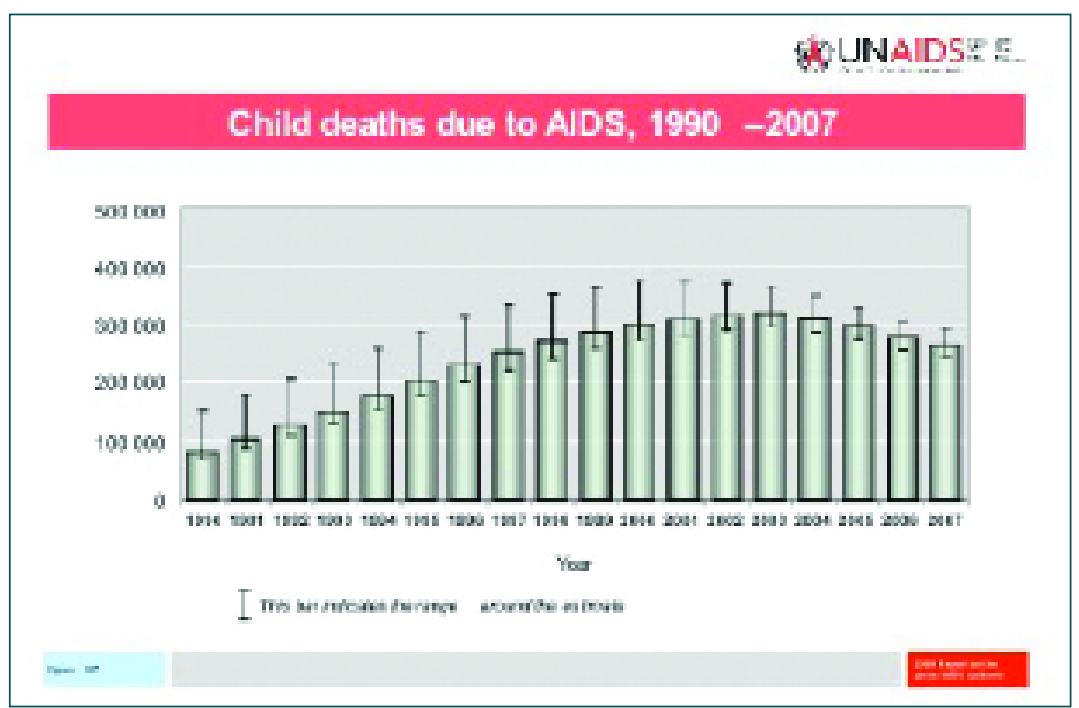

Figura 1. Mortalidade infantil pelo VIH (1990-2007)

Fonte: UNAIDS, 2008. ${ }^{14}$

\section{QUADRO II. Distribuição dos casos de transmissão vertical por ano de diagnóstico

\begin{tabular}{l|rrrrrrrrr} 
Ano de diagnóstico & $\leq 1999$ & 2000 & 200 & 2002 & $200 \beta$ & 2004 & 2005 & 2006 & 2007 \\
\hline Mãe/Filho & 68 & 1 & 2 & 5 & 0 & 1 & 2 & 2 & 0
\end{tabular}

Fonte: Centro de Vigilância Epidemiológica das Doenças Transmissíveis, 2008. ${ }^{16}$

de infantil ter diminuído, verifica-se que, em muitas regiões, isto não aconteceu.

Relativamente à infecção VIH, a amamentação parece contribuir para esta discrepância; é o que acontece, por exemplo, na África Subsariana. ${ }^{2,3,13}$ A nível global, os dados referentes à mortalidade infantil pelo VIH permanecem muito elevados (Figura 1). ${ }^{14}$ As crianças e os jovens com idade inferior a quinze anos são considerados um grupo vulnerável. ${ }^{10,13}$ Baseada na evidência, esta disparidade verifica-se, também, na diferença de género, sendo o feminino mais vulnerável à infecção. ${ }^{13}$

$\mathrm{Na}$ transmissão vertical, constata-se que muitas mulheres, desconhecendo a sua seropositividade, podem infectar o seu filho durante a gravidez, parto e através do aleitamento materno. ${ }^{4,13,15}$

A prevenção da transmissão do VIH da mãe para o filho é efectuada através da implementação de medidas, clínicas e terapêuticas, na grávida infectada e no recém-nascido. No entanto, em Portugal verifica-se que, apesar da existência de diversas opções terapêu- ticas, surgidas na última década, ainda existem casos de infecção na criança por transmissão vertical (Quadro II). ${ }^{16}$

Apesar dos benefícios da amamentação, a transmissão do VIH através do leite materno já foi comprovada há muito tempo. O momento exacto em que o bebé fica infectado com o VIH não é fácil de determinar, pois pode não ser possível distinguir entre a transmissão que ocorre durante o parto e que ocorre no início da amamentação. A quantidade de leite materno ingerida e os seus componentes (anticorpos, imunoglobulinas, lactoferrina e outros) diferem no colostro, leite de transição e no leite maduro, não sendo possível relacioná-los; por outro lado, há a diferença entre a maturidade do sistema imunológico do recém-nascido e duma criança. Estudos sugerem que as primeiras semanas de vida podem ser um período de alto risco de transmissão do VIH. ${ }^{3,4,15}$

As grávidas em fase avançada de doença têm maior probabilidade de transmissão do VIH ao seu bebé e a 
viabilidade de sobrevivência infantil é reduzida. A terapêutica anti-retroviral efectuada por estas mulheres beneficia, não só o seu estado de saúde, como também promove a vida do seu filho. ${ }^{13}$

O tipo de alimentação infantil, leite materno em exclusivo ou misto, também interfere no mecanismo de aquisição da infecção..$^{2,3,4,7,10} \mathrm{~A}$ mucosa intestinal da criança pode ser lesada por ingerir leite de vaca, por reacções alérgicas a alimentos complementares ou por infecção. A permeabilidade intestinal altera-se, facilitando a entrada do vírus, assim como a colonização da flora microbiana. Se a criança for amamentada exclusivamente, a probabilidade de transmissão é menor. ${ }^{2,3,8}$

As pesquisas mostram que há um aumento do risco de aquisição do VIH quando o aleitamento materno é combinado com a administração de alimentos sólidos. ${ }^{3,10}$

Além disso, a probabilidade de sofrer de doenças infantis (diarreia, desnutrição, pneumonia, outras) é elevada nas crianças que não fazem aleitamento materno exclusivo e que vivem em condições precárias, ${ }^{7,9,10,13}$ com dificuldade de acesso ao leite de fórmula durante o tempo necessário, inadequada preparação, água não potável, cuidados de saúde deficientes ou ausentes, recursos limitados, etc. ${ }^{7}$

A investigação realizada a dois grupos com tipo de alimentação distinta (leite materno e leite de fórmula), sugere que a amamentação por mães infectadas pelo VIH teve consequências negativas, quer para as mães, quer para as crianças. ${ }^{17}$ Outros estudos sugerem a interferência do meio em que os indivíduos estão inseridos: se este não é favorável à redução do risco, o leite materno será o mais seguro, viável, acessível e sustentável no momento. ${ }^{18}$

Diversos estudos recentes revelam que crianças infectadas com o VIH melhoram a sua sobrevivência se não ocorrer o abandono precoce do aleitamento materno. ${ }^{2,3}$

A falta de integridade da mucosa oral infantil (por exemplo, por candidíase) é uma possível porta de entrada para o VIH. ${ }^{2,3}$

São apontados como factores maternos que aumentam o risco de transmissão do VIH através da amamentação: a seroconversão durante a lactação; os clínicos; os virológicos; a carga viral quer no plasma, quer no leite materno; a duração do período da amamentação e o estado nutricional. A presença de alterações na mama e mamilos, como mastite, abcesso e fissuras, contribuem, igualmente, para a passagem do vírus. ${ }^{2,3,4,7,9,13}$ Surge, então, o dilema, quando temos, por um lado, o risco de transmissão do VIH pelo leite materno, e, por outro, a impossibilidade de uma alimentação de substituição adequada, correndo os bebés o risco de contraírem doenças infantis potencialmente fatais. ${ }^{2,3,7,13}$

Com base em novas evidências, a Organização Mundial da Saúde tem directrizes sobre a alimentação do lactente e a transmissão do VIH, em contextos mundiais de empobrecimento generalizado, a saber: ${ }^{7,13}$

- deve continuar a depender de circunstâncias individuais da mãe infectada pelo VIH, do seu estado de saúde e da situação local, tendo em conta os serviços de saúde disponíveis e considerando o apoio e o aconselhamento que provavelmente receberá;

- a amamentação exclusiva nos primeiros seis meses é recomendada, salvo se a substituição não for aceitável, possível, acessível, sustentável e segura;

- perante a substituição da amamentação, obedecendo aqueles critérios (aceitável, possível, acessível, sustentável e segura), evitar toda a forma de amamentação pela mulher infectada pelo VIH;

- se, aos seis meses, a substituição da amamentação não cumprir os critérios (aceitável, possível, acessível, sustentável e segura) recomenda-se continuar a amamentar e dar alimentos complementares, enquanto mãe e bebé continuam a ser regularmente avaliados. A amamentação deve cessar logo que uma dieta segura e nutricionalmente adequada possa ser oferecida;

- qualquer que seja a decisão sobre a alimentação, os serviços de saúde devem manter a vigilância de saúde dos bebés expostos ao VIH e manter o aconselhamento e o apoio, principalmente nos momentos em que a decisão da alimentação deve ser reconsiderada (diagnóstico infantil precoce, aos seis meses de idade);

- quando se sabe que as mães e os bébés estão infectados pelo VIH, deve-se encorajar, claramente, a amamentação;

- o aconselhamento, informação e apoio durante o período pré-natal é fundamental para as mulheres fazerem a escolha informada do tipo de alimentação infantil;

- as crianças e mães expostas aoVIH necessitam de in- 
tervenções de saúde e de sobrevivência infantil, relacionadas com a prevenção do vírus, tratamento e cuidados;

- disponibilizar o teste de detecção de anticorpos contra o VIH;

- apoiar a prevenção primária em mulheres com testes negativos durante a gravidez, parto e no período da amamentação.

Para as mães que não têm a alternativa de obter leite de fórmula, deve-se, sempre que possível, preservar o leite materno com as suas inigualáveis qualidades e inactivar o VIH (pasteurização a $62,5^{\circ} \mathrm{C},{ }^{19}$ aquecimento a $\left.56^{\circ} \mathrm{C}\right)^{20}$. Assim, a extracção e tratamento do leite materno permite à criança uma transição mais segura para outros tipos de alimentos e, simultaneamente, ao cessar a amamentação, reduz o risco de infecção VIH. ${ }^{10}$

No entanto, parece ainda ser necessária investigação mais aprofundada em relação à duração da amamentação e ao modo como é feita a cessação (abrupta ou gradual). ${ }^{3}$

As estratégias de promoção do aleitamento materno e a prevenção do risco de transmissão VIH são: a adopção de comportamentos sexuais seguros, a melhoria das condições económicas e sociais e acesso ao aconselhamento e ao teste. ${ }^{7,13}$

A avaliação de programas para prevenir a transmissão da infecção pelo VIH em jovens, mulheres em idade fértil, na gravidez e pós-parto, demonstrou que a informação adequada e correcta e o desenvolvimento das competências são fundamentais na redução do risco. ${ }^{13}$

A melhor maneira de proteger as crianças contra 0 VIH é ajudar as mães a evitar a infecção.

\section{ALEITAMENTO MATERNO E O CITOMEGALOVÍRUS}

O citomegalovírus (CMV), pertencente ao grupo herpesvírus, é identificado como agente patogénico em todos os indivíduos e em qualquer faixa etária. ${ }^{21}$

Para a sua transmissão é necessário haver um contacto íntimo, não ocasional mas repetido. A sua disseminação é facilitada nas situações sócio-económicas precárias e de más condições de higiene. ${ }^{21}$

Este vírus pode ser encontrado no leite materno, saliva, fezes, urina, sémen, secreções cervicais e no sangue (leucócitos). ${ }^{21}$

Depois da infecção primária, sintomática ou assintomática, o vírus tem a capacidade de permanecer in- terminavelmente nos tecidos do hospedeiro, sendo o indivíduo possível portador. Geralmente, a infecção mantém-se latente, reactivando com o compromisso da imunidade. ${ }^{21} \mathrm{Na}$ maioria dos casos passa despercebida.

Deste modo, a infecção do feto ou do lactente pode ocorrer por transmissão das mães, na forma primária ou em reactivação, ${ }^{22,23}$ no momento do parto, na passagem do canal de parto, através das secreções vaginais ou no pós-parto, pelo leite materno. ${ }^{22,24,25} \mathrm{~A}$ presença de anticorpos maternos não evita a transmissão de CMV para o feto, mas parece diminuí-la, assim como as suas possíveis sequelas. No entanto, é necessária mais informação sobre as consequências da infecção CMV adquirida no período pós parto e nos recém-nascidos pré-termo. ${ }^{22}$

Como conclusão dum estudo comparativo entre um grupo de vinte e dois recém-nascidos prematuros que adquiriram a infecção através do aleitamento materno e um grupo de prematuros CMV-negativos, os resultados sugerem que não há diferença significativa entre eles relativamente a alterações de audição e de desenvolvimento. Contudo, os autores alertam para a necessidade de se efectuarem mais estudos neste sentido, uma vez que a amostra foi reduzida. ${ }^{22}$

Durante a gravidez não há evidência científica para se efectuar, por rotina, a detecção do CMV. No entanto, em mulheres com profissões consideradas de risco (serviços de pediatria, creches, unidades de hemodiálise, de transplantes e outros) deverá realizar-se a pesquisa de anticorpos específicos. ${ }^{21}$

A amamentação não é contra-indicada em mães CMV positivas antes do parto. ${ }^{10,22,24}$ Os recém-nascidos não amamentados também podem ser infectados por outras vias. $^{21}$

Os bébés prematuros com um título baixo de anticorpos maternos, filhos de mães que se tornaram CMV positivas durante a lactação, podem desenvolver a doença e apresentar sequelas. ${ }^{10,24,25}$ Nos prematuros com peso inferior a 1.500 gramas, o risco de contrair uma infecção sintomática é mais elevado. ${ }^{10}$

Deve, então, considerar-se a pasteurização do leite materno a $62,5^{\circ} \mathrm{C}$ durante 30 minutos, o que inactiva o vírus, ${ }^{23}$ e a congelação a $-20^{\circ} \mathrm{C}$, que diminui a carga viral. ${ }^{1,10}$ No entanto, há investigações que não corroboraram totalmente esta opinião, sendo necessárias mais pesquisas para se chegar a uma conclusão consensual. ${ }^{24}$ 


\section{ALEITAMENTO MATERNO E HEPATITE B}

Não existem evidências científicas de que o aleitamento materno eleva o risco de transmissão mãe-filho da hepatite B. ${ }^{1}$

Assim, a amamentação não está contra-indicada em mães HBsAg positivas. ${ }^{10}$

A vacina e a imunoglobulina específica administradas após o nascimento eliminam o risco teórico de contaminação. Aos recém-nascidos de mães HBsAg positivas deve-se administrar a dose inicial da vacina ${ }^{21} \mathrm{e}$ a imunoglobulina $(0,5 \mathrm{ml})$ nas primeiras 12 horas de vida, ${ }^{1,26}$ pelo que não se justifica adiar a amamentação.

Do mesmo modo, se o estado da mãe é desconhecido, deve-se administrar a vacina ao recém-nascido nas primeiras 12 horas de vida. ${ }^{26} \mathrm{~A}$ mãe deverá efectuar uma avaliação serológica e, se o resultado for positivo, deve ser administrada a imunoglobulina ao filho. ${ }^{26}$ No entanto, a vacina isolada é bastante eficaz.

\section{CONCLUSÃO}

O leite materno é nutritivo, dinâmico, providencia o crescimento, facilita o desenvolvimento psico-social e reduz o risco de infecções e de alergias. É o melhor alimento infantil para a criança nos primeiros seis meses de vida e posteriormente, complementado com outros alimentos.

Nos países desenvolvidos, a amamentação é contra-indicada na infecção VIH, não o sendo perante a VHB e no CMV, na maioria dos casos. No entanto, em países com elevada prevalência de VIH, em que se verifica má nutrição, morbilidade e mortalidade associadas, o bebé pode ter um risco de diminuição da sobrevivência se as mães não amamentarem.

Aconselhar as mães sobre a segurança, a sustentabilidade, a disponibilidade e a acessibilidade de opções viáveis para a alimentação infantil e apoiá-las nas suas decisões são tarefas dos profissionais de saúde.

\section{REFERÊNCIAS BIBLIOGRÁFICAS}

1. Chandran L, Gelfer P. Breastfeeding: the essential principles. Pediatr Rev 2006 Nov; 27 (11): 409-17.

2. Randa JS, Peggy H, Cota V. Infant feeding and HIV transmission. Geneva: WHO; 2005. Disponível em: http://www.who.int/nutrition/topics/Paper\%20Number\%205\%20-\%20Infant\%20Feeding.pdf [acedido em 10/06/2009].

3. WHO. HIV transmission through breastfeeding: a review of available evidence: 2007 update. Geneva: WHO; 2008. Disponível em: http://whqlibdoc.who.int/publications/2008/9789241596596_eng.pdf [acedido em 10/06/2009].

4. Kaijage T. Breastfeeding and HIV. Risks and advantages. Action Contre SIDA. 1995 Oct; (26): 2-3.

5. Calvano LM. O poder imunológico do leite materno. In: Carvalho, MR, Tamez RN, editores. Amamentação: bases científicas. Rio de Janeiro: Guanabara Koogan; 2005. p.57-65.

6. Neto MT.Aleitamento materno e infecção ou da importância do mesmo na sua prevenção. Acta Pediatr Port 2006; 1 (37): 23-6.

7. Coutfoudis A, Coovadia HM, Wilfert CM. HIV, infant feeding and more perils for poor people: new WHO guidelines encourage review of formula milk policies. Bull World Health Organ 2008 Mar; 86 (3): 210-4.

8. Edwards CA, Parrett AM. Intestinal flora during the first months of life: new perspectives. Brit J Nutr 2002 Sep; 88 Suppl 1: S11-8.

9. Westerbeek EA, van Elburg RM, van den Berg A, van den Berg J, Twisk $J W$, FetterWP, et al. Design of a randomised controlled trial on immune effects of acidic and neutral oligosaccharides in the nutrition of preterm infants: carrot study. BMC Pediatr 2008 Oct 23; 8: 46.

10. Gartner LM, Morton J, Lawrence RA, Naylor AJ, O'Hare D, Schanler Al, et al. Breastfeeding and the use of human milk. Pediatr 2005 Feb; 115 (2): 496-506.

11. Venâncio SI,Almeida H. Método Mãe Canguru: aplicação no Brasil, evidências cientificas e impacto sobre o aleitamento materno. J Pediatr (Rio J) 2004 Nov: 80 (5): S173-80.

12. Claud EC, Walker WA. Bacterial colonization, probiotics, and necrotizing enterocolitis. J Clin Gastroenterol 2008 Jul; 42 Suppl 2: S46-52.

13. UNICEF. Children and AIDS:Third Stocktaking Report. New York, NY: Unicef; 2008.

14. UNAIDS. New HIV infections among children, 1990-2007. Disponível em: http://data.unaids.org/pub/GlobalReport/2008/2008_globalreport_figure2_06_en.ppt[acedido em 13/06/2009].

15. Horvath T, Madi BC, luppa IM, Kennedy GE, Rutherford G, Read JS. Interventions for preventing late postnatal mother-to-child transmission of HIV. Cochrane Database Syst Rev 2009 Jan 21; (1): CD006734.

16. Centro de Vigilância Epidemiológica das Doenças Transmissíveis. A infecção VIH/SIDA: A situação em Portugal a 31 de Dezembro de 2007 (Doc. 139). Lisboa 2008. Disponível em: http://www.aidsportugal.com/ recursos/sida122007_fev2008.pdf [acedido em 13/06/2009].

17. Nduati R, Richardson BA, John G, Mbori-Ngacha D, Mwatha A, NdinyaAchola J, et al. Effect of breastfeeding on mortality among HIV-1 infected women: a randomised trial. Lancet 2001 May 26; 357 (9269): 1651-1655.

18. Further MG. Evidence that exclusive breast-feeding reduces motherto-child HIV transmission compared with mixed feeding. PLoS Med 2008 Mar; 5 (3): e63.

Disponível em: http://www.pubmedcentral.nih.gov/articlerender.fcgi?artid=2265760 ([acedido em 13/06/2009].

19. Orloff SL, Wallingford JC, MCDougal JS. Inactivation of human immunodeficiency virus type I in human milk: effects of intrinsic factors in human milk and of pasteurization. Hum Lact 1993 Mar; 9 (1): 13-7.

20. Jeffery BS, Mercer KG. Pretoria pasteurization: a potential method for the reduction of postnatal mother to child transmission of the human immunodeficiency virus. J Trop Pediatr 2000 Aug; 46 (4): 219-23.

21. Direcção-Geral da Saúde. Saúde Reprodutiva: doenças infecciosas e 
gravidez. Lisboa. Direcção-Geral da Saúde; 2000.

22. Vollmer B, Seibold-Weiger K, Schmitz-Salue C, Hamprecht K, Goelz R, Krageloh-Mann I, et al. Postnatally acquired cytomegalovirus infection via breast milk: effects on hearing and development in preterm infants. Pediatr Infect Dis J 2004 Apr; 23 (4): 322-7.

23. Hamprecht K, Maschmann J, Vochem M, Dietz K, Speer CP, Jahn G. Epidemiology of transmission of cytomegalovirus from mother to preterm infant by breastfeeding. Lancet 2001 Feb 17; 357 (9255): 513-8.

24. Hamprecht K, Goelz R, Maschmann J. Breast milk and cytomegalovirus infection in preterm infants. Early Hum Dev 2005 Dec; 81 (12): 989$-96$
25. Yasuda A, Kimura H, Hayakawa M, Ohshiro M, Kato Y, Matsuura O, et al. Evaluation of cytomegalovirus infections transmitted via breast milk in preterm infants with a real-time polymerase chain reaction assay. Pediatr 2003 Jun; 111 (6 Pt 1): 1333-6.

26. Direcção-Geral da Saúde. Divisão de Doenças Transmissíveis. Programa Nacional de Vacinação 2006. Lisboa. Direcção-Geral da Saúde; 2005.

Conflitos de Interesse: não assinalados

ENDEREÇO PARA CORRESPONDÊNCIA

Maria Amélia Cunha

E-mail: ma.cunha@gmail.com

\section{ABSTRACT}

Breast milk has a significant importance in the prevention of infections. It contains immunological components that make it unique and inimitable.

Following birth, the gastrointestinal and immunologic systems of the newborn adapt to extrauterine life by undergoing a process of maturation and development.

Breastfeeding should be fostered, protected and supported. Nonetheless there are rare and well-defined situations of maternal infections in which breastfeeding is counter-indicated. Such is the case of the human immunodeficiency virus (HIV) infection.

The risk of the infant contracting HIV is increasing in populations with high prevalence of HIV lacking economic conditions, hygiene and medical support.

When making the decision concerning breastfeeding, mothers should take into account both its benefits and the risks of disease transmission. The health care professional should inform, guide and support HIV positive mothers making the choice of infant feeding that is the most safe in their situation. The replacement of breast milk is recommended whenever acceptable, feasible, available, sustainable and safe. This is the most appropriate option given the fact that the baby's survival is high.

The cytomegalovirus (CMV) is found in breast milk. The infection of the fetus or infant can occur through mothers with primary infection or in the course of reactivation.

The vaccine of the hepatitis B virus (HBV) is very effective. In mothers with the hepatitis B surface antigen positive ( $\mathrm{HBs} A g)$, breastfeeding is not restricted.

Keywords: breastfeeding, prevention, infection, HIV, cytomegalovirus, hepatitis B virus. 